\title{
Measuring flood resilience: A fuzzy logic approach
}

\begin{abstract}
$\underline{\text { Abstract }}$
Flood resilience is emerging as a major component of an integrated strategic approach to flood risk management. This approach recognizes that some flooding is inevitable and aligns with the concept of 'living with water'. Flood resilience measurement has been recognized as key for making the business case for investments in resilient retrofits and adaptations and, could potentially be used to inform the design of new developments where there is a risk of flooding. The literature is however sparse on frameworks for quantifying or measuring the level of resilience of flood prone households. This study describes the development of a fuzzy logic based flood resilience measuring model, drawing on a synthesis of extant flood resilience and fuzzy logic literature. An abstraction of the flood resilience system followed by identification and characterisation of systems' variables and parameters were carried out. The resulting model was transformed into a fuzzy inference system (FIS) using three input factors; Inherent resilience (IR), Supportive Facilities (SF) and, Resident Capacity (RC). The resulting fuzzy inference system generates resilience index for households with a wide range of techno-economic and socio-environmental features. . It is concluded that the fuzzy logic based model provides a veritable tool for the measurement of flood resilience at the level of the individual property, and with the potential to be further developed for larger scale applications i.e. at the community or regional levels.
\end{abstract}

Key Words: flood risk management, resilience, measurement, retrofits, fuzzy inference

\subsection{Introduction}

Flood events globally have shown a significant increase in frequency, magnitude and the extent of damage to the built environment. The interplay of extreme weather events and rapid urbanization continues to make flooding one of the most important natural hazards worldwide (Lamond, Rose and Booth 2015) (Kotze and Reyers 2016). Recent flood events have impacted negatively on the built and natural environments, resulted in huge loss of life and caused disruption to the lives of millions with huge long term socio-economic and health implications 
(Lamond, et al. 2012) (Jha, Bloch and Lamond 2012) (Kundzewicz, et al. 2014). One third of the annual natural hazards and economic losses, and more than half of the respective victims are flood related (De Wrachien and Mambretti 2012). It is now generally agreed that a warmer climate and anthropogenic activities along various flood plains would increase the risk of floods globally (Hirabayashi, et al. 2013) (Poussin, Botzen and Aerts 2015) (Kwak, et al. 2015) (Su 2016).

A lot has been done in terms of investments in flood defence schemes and flood risk management systems across the globe to enhance our capacity to deal with flood hazards. However a major consensus among flood researchers and experts is the fact that floods cannot be altogether prevented, only that their impacts on and vulnerability of the risk prone communities can be reduced (Schelfaut, et al. 2011) (Joseph, Proverbs and Lamond 2014). Therefore there have been a number of innovations geared towards better flood risk management. According to White, et al. (2015) the first wave of innovations drove a shift from flood defence to flood risk management (FRM) incorporating a wider variety of measures. Generally, there has been a shift from structural and large-scale flood defence towards integrated flood risk management (FRM). A more recent flavor of this shift revolves around the concept of flood resilience as a major platform for flood risk management. In fact resilience thinking has become an important way for city planners and decision makers to manage flood risks (Hammond, et al. 2015).

At its most basic, resilience refers to the characteristics of a system to return to its original functionality after a disturbance. Flood resilience approaches or strategies are designed to minimize the consequences of flooding while at the same time allowing for some flooding; incorporating strategies which are more flexible and offer more opportunities for nature and landscape development (Vis, et al. 2003; de Bruijn 2004). Resilience can refer to infrastructural systems in a community, or it can be concerned with the residents in a community, either as individuals or as a demographic group. That is, resilience can be at the level of community, and/or at the property (or household) level. Flood resilience measures can be characterized either as water exclusion or water entry strategies (Rose, et al. 2016). At property level, water entry resilience measures, such as replacing permeable materials with water-resistant materials, using resilient wall plasters, replacing kitchen and bathroom units with plastic units and raising electrical sockets, are designed to minimize flood damages when floodwater actually enters a property (Owusu, Wright and Arthur 2015). Water exclusion strategies include measures; like 
elevation of structure above expected flood level, dry floodproofing, and flood barriers (Maqsood, et al. 2016); designed to keep flood water from entering a property. Flood resilience at household level includes aspects of community level resilience which, according to Hammond, et al. (2015), is characterized by capabilities including; being able to avoid damage through the implementation of structural measures, to reduce damage in the case of a flood that exceeds a desired threshold, to recover quickly, and to adapt to an uncertain future.

Flood resilience, being an emerging concept, still highlights a number of issues worthy of further FRM research and practice interest. Although resilience strategies are expected to result in improved flood risk management and deserve careful evaluation, there are however no adequate, methods to quantify resilience (de Bruijn 2004). Even the definition of resilience is fluid and emerging with wide variation in the ways it is understood and applied (Park and Brooks 2015). According to Fisher (2015) there are more than 70 definitions of resilience in the scientific literature varying between two extremes of recovery resilience and adaptive resilience. We believe that the mix of FRM policies and practices will be influenced by where in the definition spectrum the term is adopted. For instance the British Standards Institution (BSI) characterizes flood resilience measures as those measures that can be incorporated into the building fabric and/or fixtures and fittings that can be installed, to reduce the consequences of flood water entering the property while flood resistance are refers to the construction of a building in such a way as to prevent or minimize floodwater entering the building and damaging its fabric (BS $85500,2015)$.

There have been a number of developments in the concept and practice of resilience in recent years. One of such is that flood resilience is moving away from equilibrium resilience to adaptive, evolutionary, and social-ecological resilience ( $\mathrm{Su}, 2016)$. While equilibrium resilience deals with the idea of 'bouncing back', adaptive resilience embraces the idea of 'moving forward' such that the disturbed system evolves into a more robust one after recovery ( $\mathrm{Su}, 2016)$. Unfortunately the diverse definitions of resilience in the literature make its meaning ambiguous (Nyström, et al. 2008).

Meanwhile, Schelfaut, et al. (2011) identified some three gaps or grey issues that have limited the translation of the resilience concept into management practice. Firstly, citing Folke (2006), Gallopin (2006), Klein, et al. (2003) they identified a lack of conceptual definitions of resilience which are consistent with operational use. Secondly, they argued that the concept of 
flood resilience and the ways to enhance it are not sufficiently known by flood managers and stakeholders. Thirdly, that resilience is difficult to measure and may vary from system to system and from one kind of disturbance to another.

We observe that although there has been considerable research directed towards addressing these gaps in recent times; many of these issues remain open for discussion and further research. According to $\mathrm{Su}$ (2016), the question of how to measure resilience still remains relevant in the context of FRM. According to Cutter (2016) the need to reduce losses associated with disasters by implementing proactive actions such as capacity building or making infrastructure and communities more resilient are stimulating interest in resilience at all levelslocal, national, and international and resilience quantification is a key driver of this interest.

Meanwhile given the socio-technical, socio-economic and human factors involved in resilience, as well as the probabilistic nature of the occurrence and impact level of flood events it is obvious that valid models describing the flood hazard and flood risk relationship will be a non linear and complex one (Davidson, et al. 2013). Also given the abstract nature and the subjectivity that characterize the concept of resilience (Cumming, et al. 2005) many aspects of the data and information required for flood risk evaluation will be available only in subjective, vague, linguistic forms: this is especially true when interactions of human and socio-technical factors are considered in flood resilience system analysis. In fact, the abstract and multidimensional nature of the concept of resilience makes it difficult to operationalize (Cumming, et al. 2005). In many real life situations, resilience information items are imprecise, incomplete, vague and subjective (Kotze and Reyers 2016); the type of information characterizing problems within the domain of fuzzy logic (Zadeh, 1996) (Zadeh, 1994) (Chakraborty, Chakraborty and Mukherjee 2016). For instance Wingfield, e tal (2005) noted that guidance on resilient building has been developed on the basis of expert opinion and extrapolation from known performance under nonflood conditions due to the lack of readily available field data on how flooded structures, components and materials behave. The aim of this study therefore is to develop a flood resilience measuring model using the concept of fuzzy logic. The specific objectives are to 1) study and identify the various critical elements and structure of the flood resilience system at property level in flood prone areas, 2) develop a fuzzy inference model of the flood resilience system and 3) apply the model to quantify resilience at household level. 
Although there have been attempts to measure resilience, most of the reported works in the literature have been in the context of ecological resilience, social resilience, social-ecological resilience, and economic resilience (Cumming, et al. 2005) (Van Nes and Scheffer 2007) (Sensier, Bristow and Healy 2016), other are adolescent and health resilience (Ahern, et al. 2006) (Mallak 1998) (Naglieri, LeBuffe and Ross 2013) with the literature sparse on the measurement of flood resilience (Kotze and Reyers 2016) (Birgani and Yazdandoost 2016) especially at property level.

\subsection{Justification}

According to Kotze and Reyers (2016) who cited Walker, et al. (2002) Carpenter, et al. (2001), managing and fostering the flood resilience of a system requires being able to measure where, and how much resilience resides in a system. It is also agreed that improving the resilience properties of buildings to better cope with flooding will support moving toward more floods resilient cities (Golz, Schinke and Naumann 2015). However information is sparse on how to quantify the overall contribution or impact of flood resilience measures and technologies on flood resilience improvement. For instance, Joseph, et al. (2014) noted that while there is high level of awareness among UK property owners in flood prone communities about resilience measures, the level of implementation of these measures is very low; only $10 \%$ of owners claimed to have implemented a full package of these. Resilience measurement has been recognized as key for making the business case for investments in resilient retrofits and other measures (Cutter 2016).

Review of academic literature and policy documents shows that increased attention is being given to flood resilience as sustainable means of FRM in recent times. According to (Garvin, Hunter, et al. 2016), the shift towards the increased adoption of flood resilience enhancement as key solution to flood risk requires an increase in responsibility for a variety of stakeholders, including property owners. There has also been an apparent consensus that increasing resilience makes economic sense (Zurich Insurance Group Ltd 2015) which should naturally encourage and boost investment in flood resilience measures. However (Garvin 2014) suggested that a range of incentives will be needed to increase such investment that can improve uptake of property level protection and other resilience measures, thereby creating resilient 
buildings. One of such incentives revolves around being able to quantify and measure the impact of investment into resilient measures.

An easy to use model for measuring and predicting the resilience of buildings and properties can provide a basis for a scaled up model applicable at any level and thus be useful for formulating and evaluating disasters control and management strategies. National and transnational emergency management agencies, urban planning and regulatory bodies, insurance companies, estate managers and other stakeholders are potential users who can benefit from the model. In particular the model can form a basis for making the business case for required investment in resilience measures and retrofits by home and property owners in flood prone areas. Therefore an easy to use and an acceptable measuring system for indexing the benefits of resilient retrofits and measures will improve the adoption of these measures by property owners and other stakeholders.

\subsection{The fuzzy logic: A general Overview}

Fuzzy set theory provides a mathematical tool for modeling uncertain, imprecise vague and subjective data which represents a huge class of data encountered in most real life situations. The fuzzy logic (FL) concept, introduced in 1965 by Lot A. Zadeh, is an extension of the classical set theory of crisp sets. FL, like humans accommodates grey areas where some questions may not have a clear Yes or No answer or black and white categorization. According to Zadeh, (1996), 'Fuzzy Logic = Computing with Words.' Fuzzy Logic combines linguistic variables; which are equivalence of mathematical variables, whose values are words or sentences; with fuzzy if-then rule, in which the antecedent and consequents are propositions containing linguistic variables, to achieve lossy data compression (Zadeh, 1994). This underlines the characteristics of FL to mimic human reasoning and capability to summarize data and focus on decision-relevant information in problems involving incomplete, vague, imprecise or subjective information.

The literature is replete with the applications of fuzzy logic, fuzzy set theories, fuzzy inference and other associated fuzzy computing concepts in a wide range of problems. The fuzzy expert system technique, which adopts fuzzy inference elements like membership functions, fuzzy logic operators, and if-then rules, is one of the successful applications of fuzzy logic as problem solving tool (Oladokun and Oyewole, 2015). Fuzzy inference allows the mapping from 
a given input to an output as a basis from which decisions can be made or patterns discerned using fuzzy logic (Oladokun and Emmanuel, 2014).

Fuzzy logic has found extensive applications in environmental management related issues (Dey and Jana 2016). In Chakraborty, et al. (2016) fuzzy logic was applied based to the detection of Parkinson's disease while Lincy and John (2016), Dash and Dash (2016) applied fuzzy logic to stock trading decision making problems. Fuzzy inference system was used to model labour productivity in the construction sector (Assefa and Robinson, 2016) and for drought prediction by Awan and Bae (2016). A common feature of these fuzzy logic applications revolves around the fact that the problems are based on subjective and non precise data, as well as expert knowledge mining; features characterizing flood resilience measurement.

\subsection{Methodology}

The sequence of activities in the process include: an abstraction of the flood resilience system; followed by identification and characterisation of relevant systems' variables and parameters; then transformation of model into fuzzy inference system equivalence; leading to system testing and validation.

\subsection{Resilience system: An abstraction and conceptual model}

We are proposing an input output model where resilience, the output, is a function of some observable input factors, with interactions between them. The states and interactions of these input factors influence and determine the resilience level of the system exposed to flood hazard. The input factors will be determined through the aggregations of insights extracted from the literature, direct general observation, and expert knowledge mining and reflective analysis of the problem. Generally input factors can be decomposed by brainstorming or check listing techniques (Zeng, An and Smith 2007). The checklist approach is more amenable to automation and suitable for the use of non experts; we will adopt this approach in this study.

\subsubsection{Key questions}

The following research questions were considered in the process of model and system development

1. What are the system quantities or factors that influence flood resilience at the property level?

2. Which of these quantities can be altered by retrofitting and other measures? 
3. What are the functional or operational categories into which these variables fall?

4. What are the suitable fuzzy logic elements that best represent this system?

\subsubsection{Resilience input factors and categorization}

Review of literature was carried out to characterize relevant factors that impact on resilience of a building in order to identify a basis for appropriate categorization. For instance, Witt, Lill and Nuuter, (2015), noted that property level flood resilience measures can be grouped as those that increase a building's resistance to flooding (e.g. by preventing flood waters entering the building - door seals, air brick covers, toilet seals) and those that increase a building's resilience (i.e. measures that minimize damage and promote recovery from a flood event waterproof fittings and finishes, raised electrical sockets, raised washing machines and built-in ovens); this agrees with the study of Kreibich, et al. (2005) where these property level precautionary measures, mostly technical, were identified and characterized. Also in a comprehensive and well cited report, by Hawkesbury-Nepean Floodplain Management Steering Committee (2006), detailed flood aware design features and principles were characterized. While in a recent study Diakakis, et al.(2017) systematically summarized a survey of literature sources on building features and properties that optimize flood performance of a building system. The insights gained from these previous studies enabled us establish an informed basis for consolidating these factors into some functional classification suitable for fuzzy inference modeling. We observed that, in this context, the various flood aware design features of a building may be categorized into two broad classes; 1) those design features that relate with the primary function of a building system (tagged 'Inherent resilience') and 2) those features that have been added for the purpose of flood risk management (tagged 'supportive facilities'). Furthermore we observed the need to include the human factor dimension (tagged Resident capacity) which was not considered in many of these studies. This third class will account for the impact of residents' behavior on the performance of a building's flood resilience features. Hence we are proposing a 3-dimensional input variable model of the building -flood resilience system which will capture the resistance and resilience parameters as identified in Witt, et al. (2015) and Kreibich, et al. (2005) as well as incoporates the human factor. Each dimension represents a set of related variable features or quantities. The three broad dimensions or categories which interact as shown 
in Figure 1 are: 1) Inherent Resilience (IR), 2) Supportive Facilities (SF) and, 3) Resident Capacity (RC). We consider this three input model compact enough for efficient and effective fuzzy system modeling.

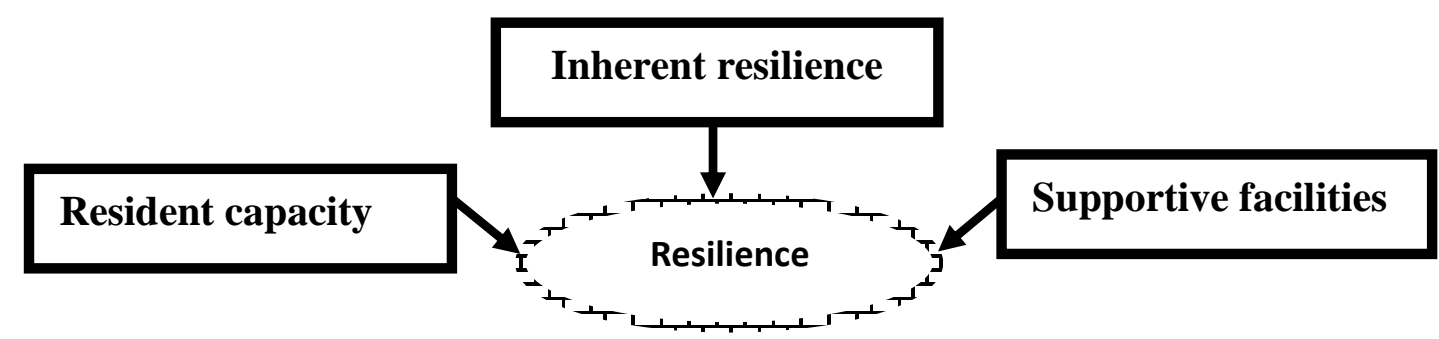

Figure 1: Three input factor resilience system

\subsection{The Fuzzy Inference Model}

The Mamdani fuzzy Inference approach will be adopted for mapping the input factors into an index system that can measure resilience. The Mamdani fuzzy inference (Mamdani and Assilian 1975) approach is most suitable for modeling expert opinion. The proposed fuzzy Inference system (see Figure 2) is characterised by the fuzzy inference linguistic variables and their term sets, the membership functions for the fuzzification and defuzzification processes, and the fuzzy rules.

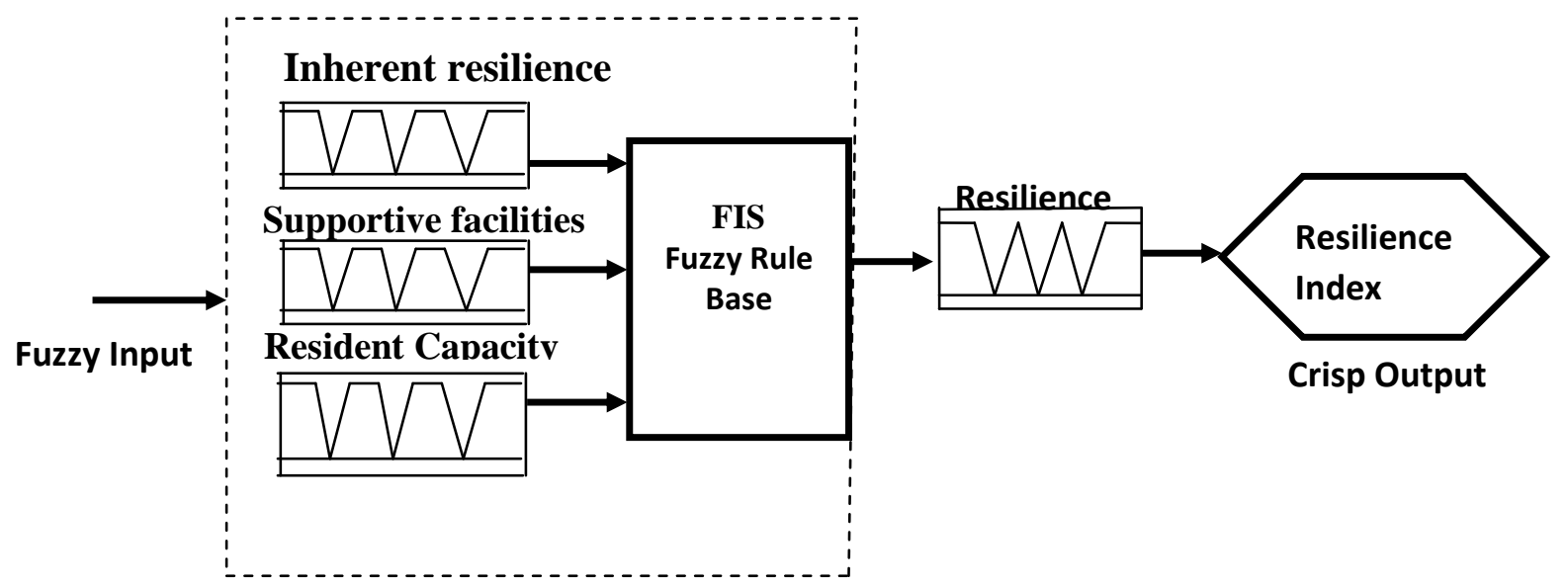

Figure 2 Resilience measurement fuzzy inference systems 


\subsubsection{Linguistic variables, term sets and fuzzy rules}

The three inputs factors and the output factor we have adopted are expressed as fuzzy expressions using appropriate linguistic variables and the membership functions. Table 1 summarizes the terms set to the variables, along with the membership functions adopted for the fuzzification and defuzzification. The fuzzy rule base consists of several fuzzy rules which are the linguistic IF-THEN constructions that mimic a typical human expert's interpretations of the interactions and states of the input variables and their consequences on the output variable. The proposed system has a rule base made up of twenty seven rules, (see Table 2 for sample fuzzy rules and appendix 1 for the full list).

Table 1 Linguistic Variables Term set and Membership functions

\begin{tabular}{|c|c|c|}
\hline Linguistic Variables & Term sets & Membership function \\
\hline \multirow{3}{*}{$\begin{array}{c}\text { Inherent resilience } \\
\text { Input 1 }\end{array}$} & Poor & Zfunction \\
\cline { 2 - 3 } & Normal & Gaussian \\
\hline \multirow{2}{*}{$\begin{array}{c}\text { Supportive facilities. } \\
\text { Input 2 }\end{array}$} & High & Sfunction \\
\cline { 2 - 3 } & Inadequate & Zfunction \\
\cline { 2 - 3 } & Marginal & Gaussian \\
\hline \multirow{2}{*}{$\begin{array}{c}\text { Resident Capacity. } \\
\text { Input 3 }\end{array}$} & Adequate & Sfunction \\
\cline { 2 - 3 } & Low & Zfunction \\
\cline { 2 - 3 } & Normal & Gaussian \\
\hline \multirow{2}{*}{$\begin{array}{c}\text { Resilience } \\
\text { Output }\end{array}$} & High & Sfunction \\
\cline { 2 - 3 } & Very Low & Zfunction \\
\cline { 2 - 3 } & Low & Pifunction \\
\cline { 2 - 3 } & Average & Gaussian \\
\hline
\end{tabular}


Table 2: Sample rules of the FIS Rule Base

\begin{tabular}{|l|l|l|}
\hline Rules premise & Rules Consequence & Weight \\
\hline If (IR is poor) \& (SF is inadequate) \& (RC is low) THEN & (Resilience is very low) & 1 \\
If (IR is poor) \& (SF is marginal) \& (RC is normal) THEN & (Resilience is low) & 1 \\
If (IR is poor) \& (SF is Adequate) \& (RC is high) THEN & (Resilience is average) & 1 \\
If (IR is normal) \& (SF is inadequate) \& (RC is low) THEN & (Resilience is very low) & 0.7 \\
If (IR is normal) \& (SF is Adequate) \& (RC is low) THEN & (Resilience is low) & 1 \\
If (IR is high) \& (SF is Adequate) \& (RC is normal) THEN & (Resilience is high) & 0.7 \\
If (IR is high) \& (SF is Adequate) \& (RC is high) THEN & (Resilience is high) & 1 \\
\hline
\end{tabular}

\subsection{Model Application Template}

In order to apply the fuzzy inference system (FIS) there is a need to develop a standardized and easy to use parameterisation template. For this demonstration we have chosen a checklist approach which returns a score on the scale of 1 to 10 for each variable based on the human experts' assessment. An extensive report on post flood building repairs by Garvin, et al. (2005) and from other sources (Maqsood, et al. 2016), (Rose, et al. 2016) were used as a guide to identifying the features of a resilient building, while studies such as Tunstall et al.,( 2007) and (Cutter, Burton and Emrich 2010) Cutter et al (2010) provide features of socio-economic and demographic parameters that characterize residents' capacity to recover from hazards.

The following contextual descriptions of the input and output variables provide guidelines for generating a checklist items of scoring.

\subsubsection{Inherent Resilience (IR)}

This captures the features, specifications and inbuilt physical characteristics of a building that minimize the impact of its exposure to flood water. Inherent resilience consists of water entry and water exclusion features inbuilt into a building. They are permanent features of a property that cannot be removed without alteration to the building. This inherent resilience is essentially a 
function of the architectural, material and construction features of a building. For ease of application the features of IR are categorized into three groups as shown in Table 3.

Table 3 Dimensions and guidelines for scoring Inherent Resilience (score 0 to 10)

\begin{tabular}{|c|c|c|}
\hline Dimension/ Rating & Descriptions of Dimensions & Implications on flood impact \\
\hline \multirow[t]{2}{*}{$\begin{array}{l}\text { 1. Architecture } \\
\text { and building } \\
\text { design }\end{array}$} & $\begin{array}{l}\text { 1. No of floors available to each } \\
\text { occupant. Eg single or double } \\
\text { storey; multi storey structure }\end{array}$ & \multirow{3}{*}{$\begin{array}{l}\text { Maximum or safe indoor flood } \\
\text { level } \\
\text { Maximum or safe outdoor flood } \\
\text { level } \\
\text { Flood accumulation rate: } \\
\text { protection of outdoor properties } \\
\text { (eg cars) Reaction time, etc }\end{array}$} \\
\hline & $\begin{array}{l}\text { 2. Minimum entrance level height } \\
\text { 3. Environment landscape }\end{array}$ & \\
\hline $\begin{array}{l}\text { Min score } 0 \\
\text { Max score } 4\end{array}$ & $\begin{array}{l}\text { 4. Perimeter wall height/ design and } \\
\text { strength }\end{array}$ & \\
\hline \multirow{2}{*}{$\begin{array}{l}\text { 2. Materials } \\
\text { specifications } \\
\text { and type }\end{array}$} & $\begin{array}{l}\text { 1. Building wall type (Water resistant } \\
\text { or not, plastered or exposed. }\end{array}$ & \multirow{4}{*}{$\begin{array}{l}\text { Ease, effectiveness and cost of } \\
\text { post flood drying. } \\
\text { Ease and effectiveness salvaging } \\
\text { to secure locations. } \\
\text { Extent of damage or exposure to } \\
\text { water }\end{array}$} \\
\hline & $\begin{array}{l}\text { 2. Flooring type and materials } \\
\text { Eg concrete, marble, wooden, } \\
\text { carpet or rug }\end{array}$ & \\
\hline \multirow{2}{*}{$\begin{array}{l}\text { Min score } 0 \\
\text { Max score } 4\end{array}$} & $\begin{array}{l}\text { 3. Wall furniture (paint types, } \\
\text { wooden, paper, or marble wall ) }\end{array}$ & \\
\hline & $\begin{array}{l}\text { 4. Furniture design and materials } \\
\text { eg detachable or inbuilt design; } \\
\text { water proof and non corrosive } \\
\text { materials eg plastic, glass, metals, }\end{array}$ & \\
\hline $\begin{array}{l}\text { 3. Electrical } \\
\text { installations }\end{array}$ & $\begin{array}{l}\text { 1. Electrical installations eg. Height } \\
\text { of power sockets, conduit or } \\
\text { surface wiring } \\
\text { 2. Location height of switch gear, } \\
\text { power box, internet router and } \\
\text { phone switch etc }\end{array}$ & $\begin{array}{l}\text { Influences the risk of } \\
\text { electrocution during flood. } \\
\text { Duration of access to power and } \\
\text { means of communication during } \\
\text { flood }\end{array}$ \\
\hline
\end{tabular}

\subsubsection{Supportive facilities (SF)}

Supportive facilities refer to exogenous auxiliary or backup systems available to defend the housing system and its residents from the impact of flooding. These are additional items or 
equipment procured and primarily configured for the building of interest; they are only activated in the event of flood. They are categorized and described as shown in Table 4.

Table 4 Dimensions and guidelines for scoring Supportive Facilities (score 0 to 10)

\begin{tabular}{|c|c|c|}
\hline Dimension/ Rating & Descriptions of Dimensions & Implications or impact \\
\hline $\begin{array}{l}\text { 1. Backup } \\
\text { storage space } \\
\text { Min score } \mathbf{0} \\
\text { Max score } 3\end{array}$ & $\begin{array}{l}\text { 1. Water proof safe or floatable storage } \\
\text { container } \\
\text { 2. Extra room protected by heights } \\
\text { 3. Extra room protected by wall and water } \\
\text { resistant doors } \\
\text { 4. 4. Remote space/room for storage }\end{array}$ & $\begin{array}{l}\text { Temporary protection } \\
\text { of valuables, } \\
\text { documents etc during } \\
\text { inundation }\end{array}$ \\
\hline $\begin{array}{l}2 . \quad \text { Backup power } \\
\text { and energy source } \\
\text { Min score } 0 \\
\text { Max score } 2\end{array}$ & $\begin{array}{l}\text { 1. Standby power generator } \\
\text { 2. Roof top solar panel power system } \\
\text { 3. Roof top solar heating system } \\
\text { 4. Fuel storage eg kerosene, diesel, charcoal } \\
\text { and stove } \\
\text { 5. 5. Source of water and food }\end{array}$ & $\begin{array}{l}\text { Temporary power, } \\
\text { heating and energy } \\
\text { source in case of } \\
\text { disruption to public } \\
\text { power supply. Only } \\
\text { needed if staying in house or } \\
\text { speeds recovery if public } \\
\text { supply takes time to be } \\
\text { reinstated }\end{array}$ \\
\hline $\begin{array}{l}\text { 3. Evacuation } \\
\text { Marine Transport } \\
\text { system } \\
\text { Min score } 0 \\
\text { Max score } 2\end{array}$ & $\begin{array}{l}\text { 1. Boat or raft in the house } \\
\text { 2. Life jackets } \\
\text { 3. Access to high axle vehicles, truck, } \\
\text { caravan and articulated vehicle } \\
\text { 4. Access to roof top helipads } \\
\text { 5. Safe haven to evacuate to } \\
\text { 6. Access to warning/alarms } \\
\text { 7. Safe means of access from higher floor }\end{array}$ & $\begin{array}{l}\text { Provides ease of } \\
\text { evacuation } \\
\text { Reduce damages } \\
\text { needed if not staying in } \\
\text { house maybe becomes } \\
\text { necessary }\end{array}$ \\
\hline $\begin{array}{l}\text { 4. Flood water } \\
\text { removing systems } \\
\text { Min score } \mathbf{0} \\
\text { Max score } 3\end{array}$ & $\begin{array}{l}\text { 1. Portable or mobile water pumps and hose } \\
\text { 2. Water bailing units } \\
\text { 3. Drying pump and blower }\end{array}$ & $\begin{array}{l}\text { Protection from mild } \\
\text { and low depth flood } \\
\text { Speed recovery }\end{array}$ \\
\hline
\end{tabular}

\subsubsection{Resident Capacity (RC)}

The resident capacity $(\mathrm{RC})$ measures the coping and adaptive capacity of people residing in a flood prone building. Factors such as the demography of the occupants, their awareness and past 
flood experience, level of education, their social capital, potential support from friends, families, church and neighbors define the resident capacity. They are categorized and described as shown in Table 5.

Table 5: Dimensions and guidelines for scoring Resident Capacity (score 0 to 10)

\begin{tabular}{|c|c|c|}
\hline Dimensions/ Rating & Descriptions of Dimensions & Implications or impact \\
\hline $\begin{array}{l}\text { 1. Demography } \\
\text { and health status } \\
\text { Min score } \mathbf{0} \\
\text { Max score } 3\end{array}$ & $\begin{array}{l}\text { 1. Presence of aged } \\
\text { 2. Gender } \\
\text { 3. Presence of Infants and toddlers } \\
\text { 4. All aged occupants eg retirees } \\
\text { 5. Disability of occupants; eg visual, hearing } \\
\text { or mobility impairment; mental } \\
\text { impairment } \\
\text { 6. Health status; presence of invalid } \\
\text { 7. Ethnicity/ability to communicate }\end{array}$ & $\begin{array}{l}\text { Influence physical } \\
\text { strength to cope with the } \\
\text { stress of flood }\end{array}$ \\
\hline $\begin{array}{l}2 . \quad \text { Economic } \\
\text { status } \\
\text { Min score } 0 \\
\text { Max score } 2\end{array}$ & $\begin{array}{l}\text { 1. Income level } \\
\text { 2. Tenant or home owner, } \\
\text { 3. Insurance status and policy type } \\
\text { 4. Having savings/reserve fund }\end{array}$ & $\begin{array}{l}\text { Influence ability to raise } \\
\text { fund for restorative } \\
\text { repairs }\end{array}$ \\
\hline $\begin{array}{l}\text { 5. Awareness and } \\
\text { education } \\
\text { Min score } \mathbf{0} \\
\text { Max score } 4\end{array}$ & $\begin{array}{l}\text { 1. Occupants with past flood experience or } \\
\text { not } \\
\text { 2. Level of education of occupants } \\
\text { Eg Having a flood plan? Signed up for warnings } \\
\text { 3. Employment status of occupants (working } \\
\text { families may not be present during flood) }\end{array}$ & $\begin{array}{l}\text { Influence of flood } \\
\text { memories to learn from }\end{array}$ \\
\hline $\begin{array}{l}\text { 5. Technical } \\
\text { Capacity } \\
\text { Min score 0 } \\
\text { Max score } 1\end{array}$ & $\begin{array}{l}\text { 1. Any occupants with relevant technical } \\
\text { skills such as plumbing, electrical repairs, } \\
\text { masonry, mechanical repairs etc } \\
\text { 2. Relationship or access to relevant } \\
\text { technicians } \\
\text { 3. Relationship or access to other social } \\
\text { networks } \\
\text { 4. Repair kits and tools in the house }\end{array}$ & $\begin{array}{l}\text { Influence capacity to } \\
\text { effect repairs even when } \\
\text { there is no fund }\end{array}$ \\
\hline
\end{tabular}




\subsubsection{Scoring and generating the crisp inputs}

The scoring sheet design should be simple and easy to use by non experts; the sheet generates the FIS crisp input. We propose two designs based on framework described in Table 3, Table 4, and Table 5 (Note that Table 6 summarizes the range of values for criteria).

Direct Scoring: The first design adopts a direct scoring approach where the assessor assigns numerical score within the range indicated for against each criterion as described in Table 6 . The maximum scores $\mathrm{M}_{\mathrm{ij}}$ assigned to each input dimension, as summarized, in Table 6 were obtained through mining of experts' opinion and a process of reflective analysis. This approach, which is simple and straight forward to use however requires some level of expertise in resilience concepts and may be subjective. Meanwhile recognizing that these values are comparison entities designed to measure the relative importance of the input dimensions we recommend a further study on how to develop comparison framework.

Table 6 : Scoring sheet based on guidelines in tables 3,4,5: the direct approach

\begin{tabular}{|c|c|c|c|c|}
\hline $\mathbf{S} / \mathbf{n}$ & Input factor & Dimension & Max score & $\begin{array}{l}\text { Actual } \\
\text { Score }\end{array}$ \\
\hline \multirow[t]{4}{*}{1} & \multirow{4}{*}{$\begin{array}{l}\text { Inherent } \\
\text { Resistance } \\
\text { (IR) }\end{array}$} & 1. Architecture and building design & 4 & \\
\hline & & 2. Materials specifications and type & 4 & \\
\hline & & 3. Electricals & 2 & \\
\hline & & Aggregate Score- IR & 10 & \\
\hline \multirow[t]{5}{*}{2} & \multirow{5}{*}{$\begin{array}{l}\text { Supportive } \\
\text { Facilities } \\
\text { (SF) }\end{array}$} & i. Backup storage space & 3 & \\
\hline & & ii. Backup power and energy source & 2 & \\
\hline & & iii. Evacuation Marine Transport system & 2 & \\
\hline & & iv. Flood water removing systems & 3 & \\
\hline & & Aggregate Score- SF & 10 & \\
\hline \multirow[t]{5}{*}{3} & \multirow{5}{*}{$\begin{array}{l}\text { Resident } \\
\text { Capacity }\end{array}$} & i. Demography and health status & 3 & \\
\hline & & ii. Economic status & 2 & \\
\hline & & iii. Awareness and education & 4 & \\
\hline & & iv. Technical Capacity & 1 & \\
\hline & & Aggregate Score - RC & 10 & \\
\hline
\end{tabular}


Indirect Scoring: The second score design adopts an indirect linguistic scoring approach using a modified psychometric measuring scale: a 5-point Likert scale (Albaum, 1997; Symeonaki, Michalopoulou and Kazan, 2015). In this option, the assessor's scoring is carried out using words (very poor, poor, fair, good, and very good) as described by the scoring template of Table 7a. Although this design may be appropriate and easier to use for scoring by non experts, however some additional computations (as summarized Table $7 \mathrm{~b}$ ) are required for converting the scoring to numeric values consistent with the direct scoring template of Table 6 .

These additional computations are demonstrated with the sample ratings or scores (marked $\sqrt{ }$ ) on Table 7a for the four dimensions of Supporting Facilities (SF). The indicated score implies that Backup storage space, Backup power/ energy source, Evacuation marine transport system, and Flood water removing systems were rated Very good $\left(R_{21}=4\right)$, Poor $\left(R_{22}=1\right)$, Fair $\left(R_{23}=2\right)$, and Good $\left(\mathrm{R}_{24}=3\right)$ respectively.

\section{$\underline{\text { Sample Calculations }}$}

The scoring on the Likert scale $0-4$ is prorated to the actual scale of Table 6 as follows With $A_{i j}=\frac{R_{i j}}{4} M_{i j} \quad$ giving the actual scores $\mathrm{A}_{\mathrm{ij}}(\mathrm{i}=2 ; \mathrm{j}=1 . .4)$ as follows

i. Backup storage space rated 'Very good' $A_{21}=\frac{R_{21}}{4} M_{21}=\frac{3}{4} \times 4=3.0$

ii. Backup power/ energy source rated 'Poor' $A_{22}=\frac{R_{22}}{4} M_{22}=\frac{1}{4} \times 2=0.5$

iii. Evacuation marine transport system rated 'Fair' $A_{23}=\frac{R_{23}}{4} M_{23}=\frac{2}{4} \times 2=1.0$

iv. Flood water removing systems rated 'Good' $A_{24}=\frac{R_{24}}{4} M_{24}=\frac{3}{4} \times 3=2.25$.

The Aggregate $\mathbf{S}_{\mathbf{j}}$ Score of $\mathbf{S F}$ is given by 
$S_{i}=\sum_{j \in i} A_{i j}=S_{2}=\sum_{j \in i} A_{2 j} \quad$ for $i=2$

That is

$S_{2}=A_{21}+A_{22}+A_{23}+A_{24}=3.0+0.5+1.0+2.25=6.75$

Table 7a: Scoring sheet based on guidelines in tables 3,4,5: Likert scale scoring approach

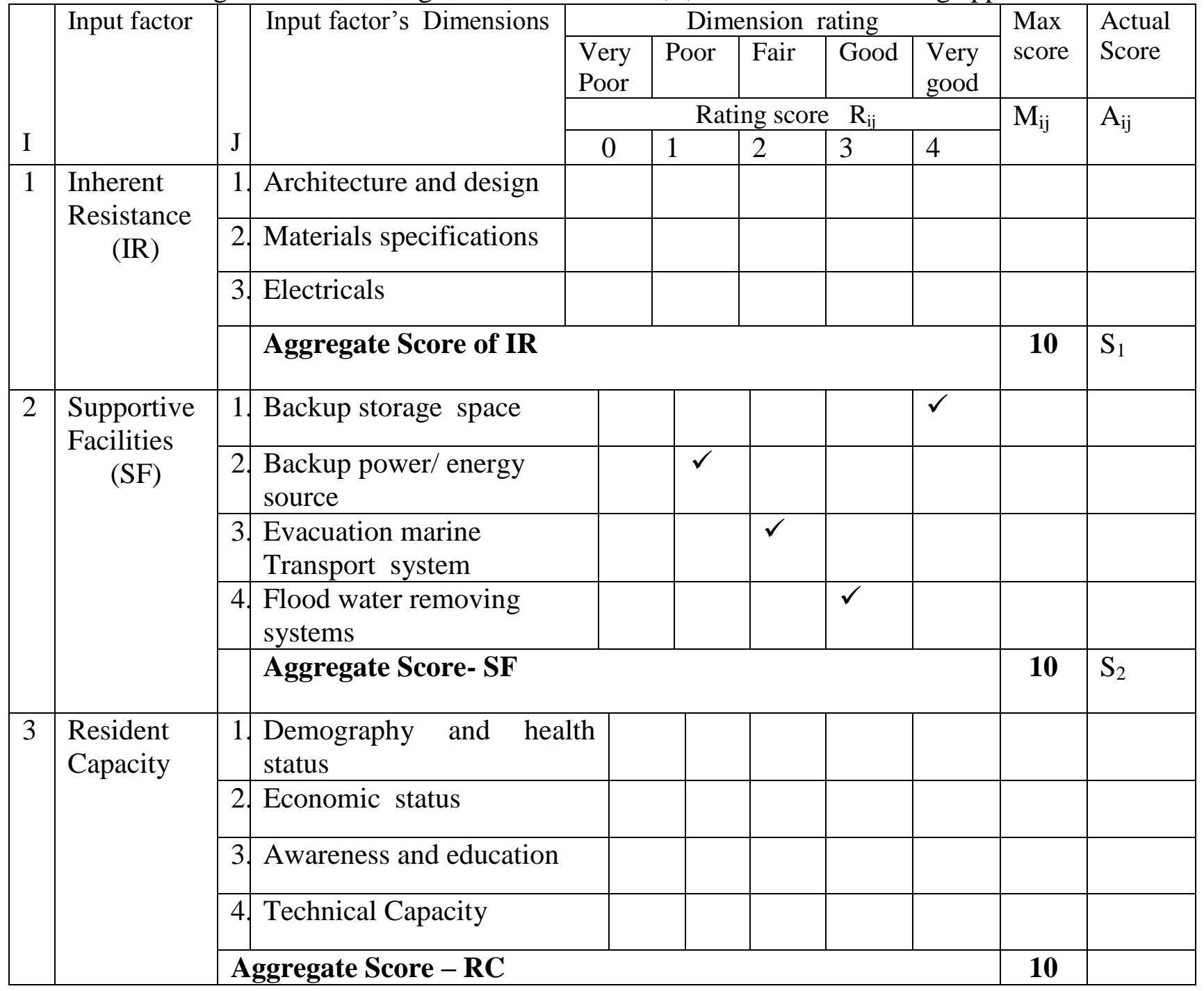


Table 7b: Notations and formulae for using scoring sheet table 7a

\begin{tabular}{cll}
\hline Notation & \multicolumn{1}{c}{ Description } & Remark \\
\hline $\mathrm{i}:$ & Index describing input factor & \\
$\mathrm{j}:$ & Index describing dimension of a factor & \\
$\mathrm{R}_{\mathrm{ij}}:$ & Likert scale rating for dimension ij. & E.g. $\mathrm{R}_{13}=1$ (Electricals in IR rated poor ) \\
$\mathrm{M}_{\mathrm{ij}}:$ & $\begin{array}{l}\text { Maximum score assignable to } \\
\text { dimension ij. }\end{array}$ & E.g. $\mathrm{M}_{21}=3$ (Backup storage space in SF) \\
$\mathrm{A}_{\mathrm{ij}}:$ & Actual score assigned to dimension ij & Where $A_{i j}=\frac{R_{i j}}{4} M_{i j}$ \\
& & Where $S_{i}=\sum_{j \in i} A_{i j}$ \\
$\mathrm{~S}_{\mathrm{i}}:$ & Aggregate score for factor $\mathrm{i}$. & Where
\end{tabular}

\subsection{Model Parameterization}

The foregoing guidelines for input factors' scoring provide a generic basis for parameterization of the FIS model. The scoring process and the output interpretation must therefore be adapted to account for environmental and location specifics as well as other socio-cultural peculiarities. A model validation process by experts is achieved by comparing the model output with real life data and experts' opinion. This involves comparing the model resilience output of household with real damage data. This process (see Figure 3) allows the model to be refined and adapted to specific local environments. The elements of the parameterization process depicted in Figure 3 are designed to minimize the subjectivity in the application of the FIS model.

Figure 3: FIS model parameterization process (here)

\subsection{Results and discussions}

An overview of the mapping characteristics of the FIS system is provided by the surface plot generated by the FIS as shown in Figure 4. The 3D plot (Figure 4) shows the entire resilience output surface generated by the infinite combinations of input factors: sample combinations are tabulated in Table 8. The shape of the resilience surface is determined by the rules and the selected membership functions used to express the term sets. Note, as indicated in Figure 4, that the rules, rules weights and the membership functions can be adjusted to vary the shape of resilience surface plots. This gives designers the opportunity to simulate various combinations of 
FIS parameters in order to arrive at design options that best capture experts' knowledge of the problem.

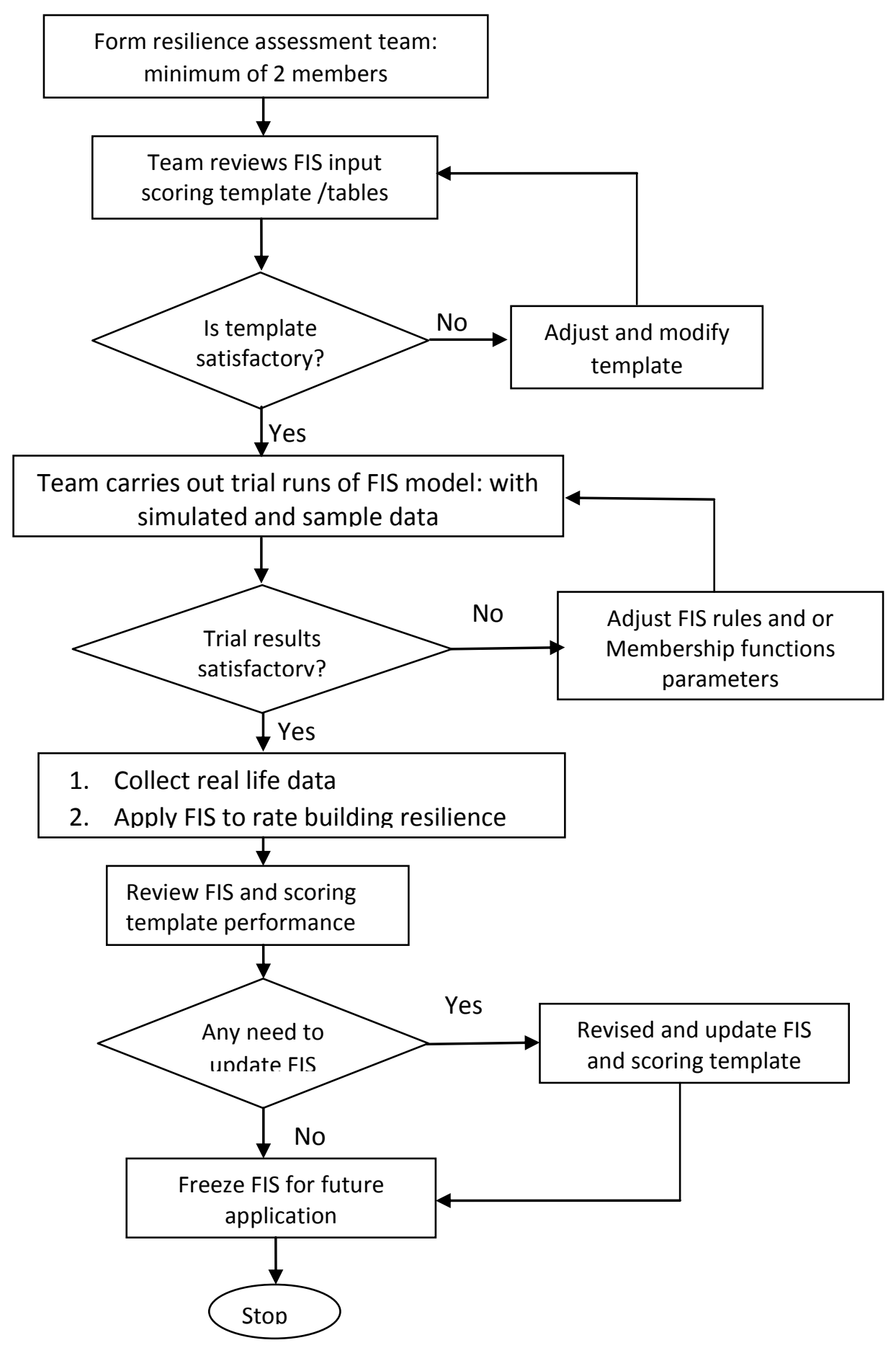

Figure 3: FIS model parameterization process 


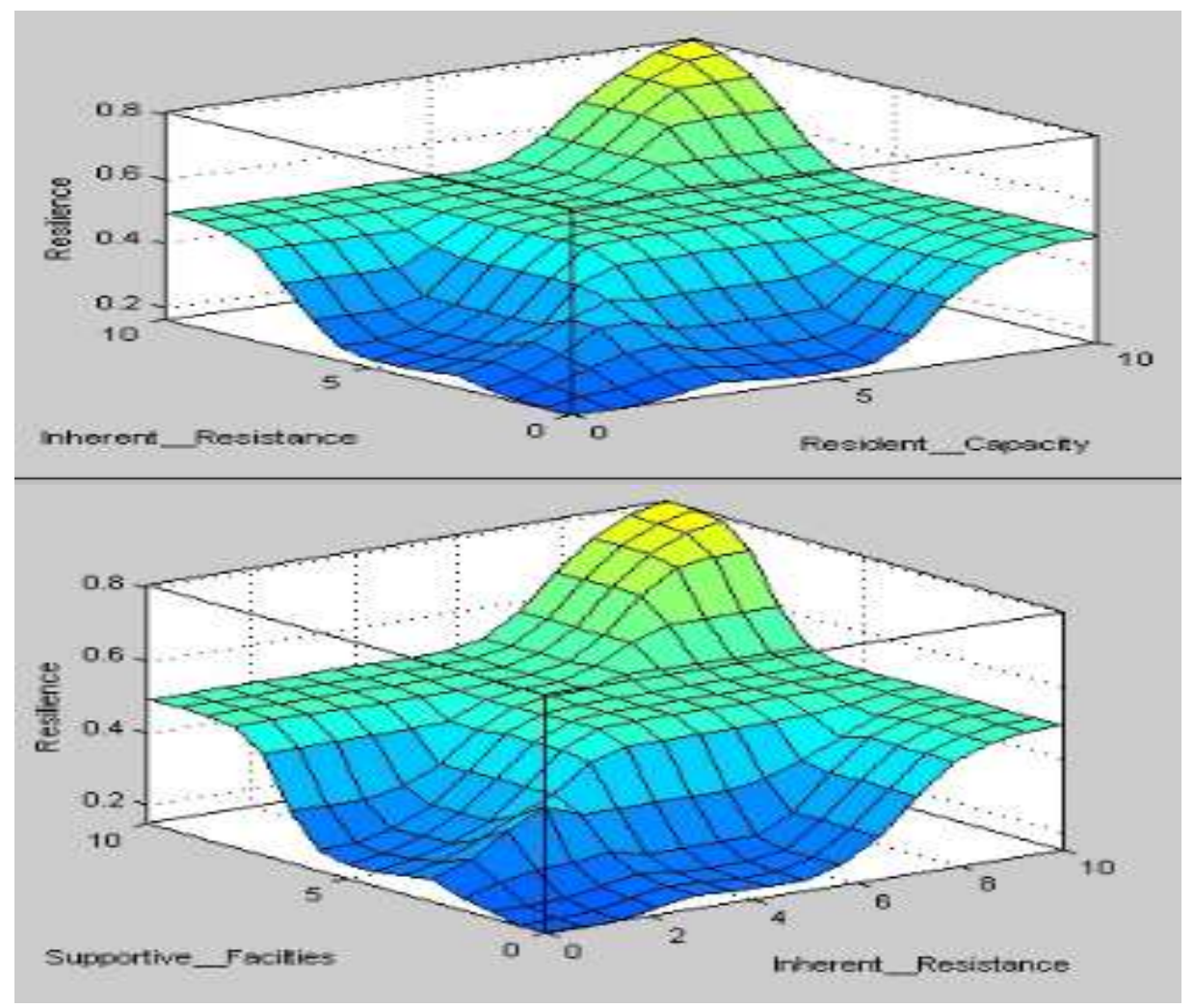

Figure 4 Resilience output surface plots

Table 8: Sample combinations of input factors

\begin{tabular}{|l|l|l|l|l|}
\hline $\mathrm{s} / \mathrm{n}$ & $\begin{array}{l}\text { Inherent } \\
\text { Resilience }\end{array}$ & $\begin{array}{l}\text { Supportive } \\
\text { Facilities }\end{array}$ & $\begin{array}{l}\text { Resident } \\
\text { Capacity }\end{array}$ & Resilience \\
\hline 1 & 2.0 & 2.0 & 2.0 & $\mathbf{0 . 1 9 5}$ \\
\hline 2 & 2.0 & 2.0 & 5.0 & $\mathbf{0 . 2 1 4}$ \\
\hline 3 & 2.0 & 2.0 & 8.0 & $\mathbf{0 . 3 0 0}$ \\
\hline 4 & 2.0 & 5.0 & 5.0 & $\mathbf{0 . 2 7 0}$ \\
\hline 5 & 2.0 & 5.0 & 8.0 & $\mathbf{0 . 4 5 2}$ \\
\hline 6 & 2.0 & 8.0 & 8.0 & $\mathbf{0 . 4 9 0}$ \\
\hline 7 & 5.0 & 2.0 & 2.0 & $\mathbf{0 . 2 1 7}$ \\
\hline 8 & 5.0 & 5.0 & 2.0 & $\mathbf{0 . 2 7 6}$ \\
\hline 9 & 5.0 & 5.0 & 5.0 & $\mathbf{0 . 4 9 4}$ \\
\hline 10 & 5.0 & 8.0 & 3.0 & $\mathbf{0 . 4 5 0}$ \\
\hline 11 & 6.0 & 9.0 & 4.0 & $\mathbf{0 . 5 0 0}$ \\
\hline 12 & 8.0 & 5.0 & 2.0 & $\mathbf{0 . 4 5 3}$ \\
\hline 13 & 8.0 & 8.0 & 5.0 & $\mathbf{0 . 6 8 2}$ \\
\hline 14 & 8.0 & 5.0 & 8.0 & $\mathbf{0 . 6 6 6}$ \\
\hline 15 & 8.0 & 5.0 & 9.0 & $\mathbf{0 . 6 7 4}$ \\
\hline 16 & 8.0 & 8.0 & 8.0 & $\mathbf{0 . 7 1 6}$ \\
\hline
\end{tabular}


Note that the value of each of the input factors for a given building can be changed or improved upon by some form of intervention. The FIS thus provide a means of visualizing and understanding the impact of the changes in any of the input factors and dimensions on the resilience output. For instance the inherent resilience (IR) of the building can be improved through appropriate retrofitting, additional supportive facilities can be procured while enlightenment and education can improve resident capacity. The FIS thus provides a tool to simulate the results of any proposed resilience intervention or retrofitting program.

\subsection{Conclusion and Recommendations}

The development of a fuzzy inference system for measuring the resilience level of households exposed to flooding has been described. A three variable mapping system was defined to model flood resilience response characteristics of a household and extends the measurement beyond the physical characteristics of a flood prone property. The resulting fuzzy inference system generates resilience index for households with a wide range of techno-economic and socio-environmental features. The fuzzy logic approach accommodates the imprecise, incomplete, vague and subjective data that characterize many real life flood risk management problems. It is concluded that the fuzzy logic based model provides a potentially veritable tool for resilience measurement and quantification at the level of the individual household. It is recommended that the fuzzy inference system measurement method proposed is subjected to empirical testing and refinement to help confirm the assumptions and assertions made. If proven successful, the model has the potential to be extended to flood resilience measurement at larger scale applications i.e. at the community level and regional level.

\section{Acknowledgement:}

i. $\quad$ This work is part of the research carried out under the Commonwealth Academic Fellowship award, NGCF-2015-99, funded by the UK government

ii. We acknowledge the support of the UI Ibadan TETFUND IBR 2016 Research Project Fund 


\section{References}

Ahern, N R, E M Kiehl, M Lou Sole, and J Byers. "A review of instruments measuring resilience." Issues in comprehensive Pediatric nursing 29, no. 2 (2006): 103-125.

Albaum, G. "The Likert scale revisited: an alternate version." Journal of the Market Research Society 39, no. 2 (1997): 331-332.

Assefa, T A, and F A Robinson. "Developing and Optimizing Context-Specific Fuzzy Inference SystemBased Construction Labor Productivity Models." Journal of Construction Engineering and Management, 2016.

Awan, J A, and D H Bae. "Drought prediction over the East Asian monsoon region using the adaptive neuro-fuzzy inference system and the global sea surface temperature anomalies." International Journal of Climatology, 2016.

Birgani, Y T, and F Yazdandoost. "Resilience in urban drainage risk management systems." Water Management : Proceedings of the Institution of Civil Engineers. ICE Publishing, 2016. 3-16.

BSI. Flood resistant and resilient construction. Guide to improving the flood performance of buildings. London: BSI Standards Limited, 2015.

Carpenter, S, B Walker, J M Anderies, and N Abel. "From metaphor to measure-ment: resilience of what to what." Ecosystems 4 (2001): 765-781.

Chakraborty, A, A Chakraborty, and B Mukherjee. "Detection of Parkinson's Disease Using Fuzzy Inference System." In In Intelligent Systems Technologies and Applications, edited by S Berretti, S Thampi and P R Srivastava, 79-90. Springer International Publishing, 2016.

Cumming, G S, G Barnes, S Perz, M Schmink, K E Sieving, and J Southworth. "An exploratory framework for the empirical measurement of resilience." Ecosystems 8, no. 8 (2005): 975-987.

Cutter, S L. "The landscape of disaster resilience indicators in the USA." Natural Hazards 80, no. 2 (2016): 741-758.

Cutter, S. L, Burton, C. G and Emrich , C.T. "Disaster Reslience resilience indicators for benchmarking baseline condirtions." Journal of homeland security and emergency management 7, no. 1 (2010): 1-24.

Dash, R, and P Dash. "Efficient Stock Price Prediction using A Self Evolving Recurrent Neuro-Fuzzy Inference System Optimized through a Modified Differential Harmony Search Technique." Expert Systems with Applications 52, no. 15 (2016): 75-90.

Davidson, J L, I E van Putten, P Leith, M Nursey-Bray, M M Elizabeth, and N J Holbrook. "Toward operationalizing resilience concepts in Australian marine sectors coping with climate change." Ecology and Society 18, no. 3 (2013).

de Bruijn, K M. "Resilience indicators for flood risk management systems of lowland rivers." International Journal of River Basin Management 2, no. 3 (2004). 
De Wrachien, D, and S Mambretti. "Mathematical models in flood management: overview, laboratory tests and case study." In Flood Risk Assessment and Management, edited by S Mambretti, 1-11. WIT Press, 2012.

Dey, S, and D K Jana. "Application of fuzzy inference system to polypropylene business policy in a petrochemical plant in India." Journal of Cleaner Production 112 (2016): 2953-2968.

Diakakis, M, G Deligiannakis, A Pallikarakis, and M Skordoulis. "Identifying elements that affect the probability of buildings to suffer flooding in urban areas using Google Street View. A case study from Athens metropolitan area in Greece." International Journal of Disaster Risk Reduction 22 (2017): 1-9.

Fisher, L. "Disaster responses: More than 70 ways to show resilience." Nature 518, no. 7537 (2015): 3535.

Folke, C. "Resilience:theemergenceofaperspectivefor social-ecologicalsystemsanalyses."

GlobalEnvironmental Change 16 (2006): 253-267.

Gallopin, G C. "Linkagesbetweenvulnerability,resilience and adaptivecapacity." Global Environmental Change 16 (2006): 293-303.

Garvin, S. A Future Flood Resilient Built Environment. BRE Trust, 2014.

Garvin, S, J Reid, and M Scott. Standards for the repair of buildings following flooding. London: Ciria, 2005.

Garvin, S, K Hunter, D McNally, D Barnett, and R Dakin. "Property flood resilience database: an innovative response for the insurance market ." FLOODrisk 2016 - 3rd European Conference on Flood Risk Management. Lyon: EDP Sciences, 2016.

Golz, S, R Schinke, and T Naumann. "Assessing the effects of flood resilience technologies on building scale." Urban Water Journal 12, no. 1 (2015): 30-43.

Hammond, M J, A S Chen, S Djordjević, D Butler, and O Mark. "Urban flood impact assessment: A state-of-the-art review." Urban Water Journal 12, no. 1 (2015): 14-29.

Hawkesbury-Nepean Floodplain Management Steering Committee. Reducing Vulnerability of Buildings to Flood Damage: Guidance on Building in Flood Prone Areas. Hawkesbury-Nepean Floodplain Management Steering Committee, 2006.

Hirabayashi, Y, et al. "Global flood risk under climate change." Nature Climate Change 3, no. 9 (2013): 816-821.

Jha, A K, R Bloch, and J Lamond. Cities and Flooding: A guide to Integrated Urban Flood Risk Management the 21st Centuries . Washington : The World bank, 2012, 631. 
Joseph, R, D Proverbs, and J Lamond. Resilient reinstatement: what can we learn from the 2007 flooding in England? Vol. 184, in Flood Recovery, Innovation and Response IV, by D Proverbs and C A Brebbia, 175-186. WIT Press, 2014.

Klein, R J.T, R J Nicholls, and F Thomalla. "Resilience to natural hazards: howusefulisthisconcept?" Environmental Hazards 5 (2003): 35-45.

Kotze, I, and B Reyers. "Piloting a social-ecological index for measuring flood resilience: A composite index approach." Ecological Indicators 60 (2016): 45-53.

Kreibich, H, A H Thieken, Th Petrow, M M"uller, and B Merz. "Flood loss reduction of private households due to building precautionary measures - lessons learned from the Elbe flood in August 2002." Natural Hazards and Earth System Sciences 5 (2005): 117-126.

Kundzewicz, Z W, et al. "Flood risk and climate change: global and regional perspectives." Hydrological Sciences Journal 59, no. 1 (2014): 1-28.

Kwak, Y, M Gusyev, B Arifuzzaman, I Khairul, Y Iwami, and K Takeuchi. "Effectiveness of Water Infrastructure for River Flood Management: Part 2-Flood Risk Assessment and Its Changes in Bangladesh." Proc. IAHS 370. 2015. 83-87.

Lamond, J E, D G Proverbs, C A Booth, and F N Hammond. "Flooding in the built environment : changing risk and overview of Impact." In Flood Hazards : Impacts and responses for the built environment, by J E Lamoond, D G Proverbs, C A Booth and F N Hammond, 1-6. CRC press Taylor and Franciis , 2012.

Lamond, J, C Rose, and C Booth. "Evidence for improved urban flood resilience by sustainable drainage retrofit." Proceedings of the ICE: Urban Design and Planning. 2015. 101-111.

Lincy, G R M, and C J John. "A multiple fuzzy inference systems framework for daily stock trading with application to NASDAQ stock exchange." Expert Systems with Applications: An International Journal 44, no. C (2016): 13-21.

Mallak, L A. "Measuring resilience in health care provider organizations." Health manpower management 24, no. 4 (1998): 148-152.

Mamdani, E H, and S Assilian. "An experiment in linguistic synthesis with a fuzzy logic controller." International Journal of Man-Machine Studies 7, no. 1 (1975.): 1-13.

Maqsood, T, M Wehner, K Dale, and M Edwards. "Cost -effective mitigation strategies for residential buildings in Australian fllood plains." International Journal of Safety and Security Enginneering 6, no. 3 (2016): 550-559.

Naglieri, J A, P A LeBuffe, and K M Ross. "Measuring resilience in children: From theory to practice." In Handbook of resilience in children, 241-259). Springer US, 2013.

Nyström, M, N A J Graham, J Lokrantz, and A V Norström. "Capturing the cornerstones of coral reef resilience: linking theory to practice." Coral Reefs 27, no. 4 (2008): 795-809. 
Oladokun, V O, and C G Emmanuel. "Urban Market Fire Disasters Management in Nigeria: A Damage Minimization based Fuzzy Logic Model Approach." International Journal of Computer Applications 106, no. 17 (2014).

Oladokun, V O, and D I Oyewole. "A Fuzzy Inference based decision support system for solving the University-Course Admission Choice Problem." International Journal of Computer Applications 112, no. 3 (2015): 1-7.

Owusu, S, G Wright, and S Arthur. "Public attitudes towards flooding and property-level flood protection measures." Natural Hazards 77, no. 3 (2015): 1963-1978.

Park, J, and C Brooks. "Local flood resiliency in an era of global climate change: understanding the multi-sectoral policy dimensions." Vt. J. Envtl. L. 17 (2015): 160-283.

Poussin, J K, W W Botzen, and J C Aerts. "Effectiveness of flood damage mitigation measures: Empirical evidence from French flood disasters." Global Environmental Change 31 (2015): 74-84.

Rose, C, J Lamond, M Dhonau, R Joseph, and D Proverbs. "Improving the uptake of flood resilience at the individual property level." Internatioanl Journal of Safety and Security Engineering 6, no. 3 (2016): 607-615.

Schelfaut, K, B Pannemans, I van der Craats, J Krywkow, J Mysiak, and J Cools. "Bringing floodresilienceintopractice:theFREEMAN project." Environmental Science \& Policy 14, no. 7 (2011): 825-833.

Sensier, M, G Bristow, and A Healy. "Measuring Regional Economic Resilience across Europe: Operationalizing a complex concept." Spatial Economic Analysis, 2016: 1-16.

Su, Y S. "Discourse, Strategy, and Practice of Urban Resilience against Flooding." Business and Management Studies 2, no. 1 (2016): 73-87.

Symeonaki, M, C Michalopoulou, and A Kazani. "A fuzzy set theory solution to combining Likert items into a single overall scale (or subscales)." Quality \& Quantity 49, no. 2 (2015): 739-762.

Tunstall, S, Tapsell, S, and Fernandez-Bilbao A. "Vulnerability and flooding: a re-analysis of FHRC data” Country Reports England and Wales, (2007)

Van Nes, E H, and M Scheffer. "Slow recovery from perturbations as a generic indicator of a nearby catastrophic shift." The American Naturalist 169, no. 6 (2007): 738-747.

Vis, M, F Klijn, K M De Bruijn, and M Van Buuren. "Resilience strategies for flood risk management in the Netherlands." International journal of river basin management 1, no. 1 (2003): 33-40.

Walker, B, et al. "Resilience management in social-ecological systems: a working hypothesis for a participatory approach." Conservation ecology 6, no. 1 (2002): 14.

White, I, A Connelly, and S Garvin. "towards best practice in property level flood protection." Town \& Country Planning 83 (2015): 82-87. 
Winderl, T. Disaster resilience measurements: stocktaking of ongoing efforts in developing systems for measuring resilience. United Nations Development Programme (UNDP)., 2014.

Wingfield, J, M Bell, and P Bowker. Improving the flood resilience of buildings through improved materials, methods and details. Leeds Metropolitan University, 2005.

Witt, E, I Lill, and T Nuuter. "Comparative Analysis of Current Guidance for the Evaluation of Building Retrofit Investments." Procedia Economics and Finance 21 (2015): 321-328.

Zadeh, L A. "Fuzzy logic= computing with words." Fuzzy Systems, IEEE Transactions on 4, no. 2 (1996): 103-111.

Zadeh, L A. "Soft computing and fuzzy logic." IEEE software 11, no. 6 (1994): 48.

Zeng, J, M An, and N J Smith. "Application of a fuzzy based decision making methodology to construction project risk assessment." journal of project management 25, no. 6 (2007): 589-600.

Zurich flood resilience alliance. Can flood resilience be measured? An innovative collaborative approach may do just that. Zurich flood resilience alliance, 2014.

Zurich Insurance Group Ltd. Beyond response and recovery:an introduction to the Zurich flood resilience program. Zurich Insurance Group Ltd, 2015.

Appendix 1: Fuzzy rules

\begin{tabular}{|c|c|c|}
\hline Rules premise & Rules Consequence & Weight \\
\hline If (IR is poor) \& (SF is inadequate) \& ( $\mathrm{RC}$ is low) THEN & (Resilience is very low) & 1 \\
\hline If (IR is poor) \& ( $\mathrm{SF}$ is inadequate) \& ( $\mathrm{RC}$ is normal) THEN & (Resilience is very low) & 0.7 \\
\hline If (IR is poor) \& (SF is inadequate) \& ( $\mathrm{RC}$ is high) THEN & (Resilience is low) & 0.7 \\
\hline If (IR is poor) \& ( $\mathrm{SF}$ is marginal) \& ( $\mathrm{RC}$ is low) THEN & (Resilience is very low) & 0.7 \\
\hline If ( $\mathrm{IR}$ is poor) \& ( $\mathrm{SF}$ is marginal) \& ( $\mathrm{RC}$ is normal) THEN & (Resilience is low) & 1 \\
\hline If (IR is poor) \& (SF is marginal) \& ( $\mathrm{RC}$ is high) THEN & (Resilience is average & 0.6 \\
\hline If (IR is poor) \& ( $\mathrm{SF}$ is Adequate) \& ( $\mathrm{RC}$ is low) THEN & (Resilience is very low) & 0.6 \\
\hline If (IR is poor) \& ( $\mathrm{SF}$ is Adequate) \& ( $\mathrm{RC}$ is normal) THEN & (Resilience is average) & 0.7 \\
\hline If (IR is poor) \& ( $\mathrm{SF}$ is Adequate) \& ( $\mathrm{RC}$ is high) THEN & (Resilience is average) & 1 \\
\hline If (IR is normal) \& (SF is inadequate) \& ( $\mathrm{RC}$ is low) THEN & (Resilience is very low) & 0.7 \\
\hline If (IR is normal) \& ( $\mathrm{SF}$ is inadequate) \& ( $\mathrm{RC}$ is normal) THEN & (Resilience is low) & 1 \\
\hline If (IR is normal) \& (SF is inadequate) \& ( $\mathrm{RC}$ is high) THEN & (Resilience is average) & 0.7 \\
\hline If (IR is normal) \& (SF is marginal) \& ( $\mathrm{RC}$ is low) THEN & (Resilience is low) & 1 \\
\hline If (IR is normal) \& (SF is marginal) \& ( $\mathrm{RC}$ is normal) THEN & (Resilience is average) & 0.7 \\
\hline If (IR is normal) \& (SF is marginal) \& ( $\mathrm{RC}$ is high) THEN & (Resilience is average & 0.9 \\
\hline If (IR is normal) \& (SF is Adequate) \& ( $\mathrm{RC}$ is low) THEN & (Resilience is low) & 1 \\
\hline If (IR is normal) \& (SF is Adequate) \& ( $\mathrm{RC}$ is normal) THEN & (Resilience is average) & 0.8 \\
\hline If (IR is normal) \& (SF is Adequate) \& ( $\mathrm{RC}$ is high) THEN & (Resilience is average) & 0.6 \\
\hline If (IR is high) \& (SF is inadequate) \& ( $\mathrm{RC}$ is low) THEN & (Resilience is low) & 0.7 \\
\hline
\end{tabular}




\begin{tabular}{|l|l|l|}
\hline If (IR is high) \& (SF is inadequate) \& (RC is normal) THEN & (Resilience is average) & 0.7 \\
If (IR is high) \& (SF is inadequate) \& (RC is high) THEN & (Resilience is average) & 1 \\
If (IR is high) \& (SF is marginal) \& (RC is low) THEN & (Resilience is average) & 0.7 \\
If (IR is high) \& (SF is marginal) \& (RC is normal) THEN & (Resilience is average) & 1 \\
If (IR is high) \& (SF is marginal) \& (RC is high) THEN & (Resilience is high) & 0.7 \\
If (IR is high) \& (SF is Adequate) \& (RC is low) THEN & (Resilience is average) & 0.7 \\
If (IR is high) \& (SF is Adequate) \& (RC is normal) THEN & (Resilience is high) & 0.7 \\
If (IR is high) \& (SF is Adequate) \& (RC is high) THEN & (Resilience is high) & 1 \\
\hline
\end{tabular}

